\title{
Preconceptions and expectations of older adults about getting hearing aids
}

This article was published in the following Dove Press journal:

Journal of Multidisciplinary Healthcare

31 December 2010

Number of times this article has been viewed

\section{Jorunn Solheim}

ENT Department, Lovisenberg Diakonale Hospital, Oslo, Norway

Correspondence: Jorunn Solheim ENT Department, Lovisenberg

Diakonale Hospital,

Lovisenberggaten 15

$\mathrm{N}-0456$ Oslo, Norway

Tel +472322 54 29, +4797659680

Email jorunn.solheim@lds.no
Aim: The objectives of this study were to describe preconceptions and expectations of older adults about getting hearing aids and to explore the influence of hearing loss (HL), hearing aid experience, gender, age, and marital status on these preconceptions and expectations.

Methods: A total of 174 participants aged above 65 years were randomly selected from a waiting list for hearing aid fitting. Hearing threshold was tested using pure tone audiometry. A self-report questionnaire with a specific focus on preconceptions and expectations about getting hearing aids, external influences, and the psychosocial problems associated with HL and the use of a hearing aid was administered.

Results: A factor analysis revealed three factors: positive expectations, barriers, and social pressure. Cronbach's $\alpha$ was 0.847 for positive expectations and 0.591 for barriers. Cronbach's $\alpha$ was not statistically applicable to the social pressure factor, as it consisted of only one item. Adjusted linear regression analysis revealed that participants with moderate to severe HL and hearing aid experience had a significant increase in positive expectations. Male gender was associated with fewer barriers to hearing aids. Age and marital status had no influence on the three factors.

Conclusion: Less positive expectations and more problem-oriented preconceptions among subjects with mild HL may explain why hearing aids are scarcely used. Additionally, lower estimated need and modest plans for regular use among this group could mean hearing aids are not used. Rehabilitation should focus on investment of time, continuity of use, realistic expectations, and follow-up support.

Keywords: hearing aid, older adults, preconceptions, expectations, barriers

\section{Introduction and purpose}

Hearing loss (HL) is one of the most common health problems for people aged 65 years and above, ${ }^{1}$ so the growing number of hearing-impaired older adults is a natural result of our growing elderly population. ${ }^{2}$ The prevalence of hearing impairment rapidly increases with increasing age. It is estimated that it affects $\sim 48 \%$ of individuals in their $60 \mathrm{~s}, 60 \%$ in their $70 \mathrm{~s}, 3,4$ and $90 \%$ of people aged 80 years and above. ${ }^{5,6}$

The perceived need for hearing amplification may not be proportional to the high prevalence of HL. A Norwegian health screening survey found that just over $50 \%$ of older adults perceived their HL to be troublesome. ${ }^{6}$ Even among those who possess a hearing aid, a substantial proportion never or scarcely use their hearing aid. ${ }^{7-12}$ Various reasons for this have been stated, including practical and functional problems, ${ }^{13-15}$ no/poor benefit, ${ }^{14}$ and no need. ${ }^{16,17}$

Efforts have been made to identify the preconceptions and expectations of adults prior to getting hearing aids. Novice hearing aid users have been found to have 
unrealistically high expectations prior to fitting. ${ }^{18,19}$ It has been suggested that this outlook might lead to ultimate dissatisfaction if the original expectations are not met with subsequent hearing aid use. ${ }^{20}$ Experienced hearing aid users have been found to have the most positive attitudes toward hearing aids. ${ }^{21}$ A clinical study found some low but significant correlations between attitudes and measured HL. ${ }^{22}$ Stigmatization is frequently mentioned as a significant factor for having a reserved attitude toward hearing aids. ${ }^{23,24}$ In the Valby Project, which surveys hearing in elderly people aged $\geq 80$ years who are not provided with hearing aids, $62 \%$ of those surveyed reported a wish for a hearing aid to be "invisible", and $28 \%$ expressed that a hearing aid "makes you old". ${ }^{25}$ Several studies have reported a passive acceptance of hearing problems among older adults, ${ }^{21,26}$ particularly among men. ${ }^{27}$ It has been shown that many patients requesting evaluation for a hearing aid are not self-motivated but are motivated by family members or significant others in the majority of cases. ${ }^{28,29}$

Older people ( $>65$ years old) constitute the majority of hearing aid users in the industrialized world. In Sweden, this group is estimated to represent $70 \%$ of the total population of hearing aid users. ${ }^{30}$ Due to a considerable number of hearing aids not being used, we need to know why many people are not adopting or wearing them. Further knowledge about preconceptions and expectations toward hearing aids among older adults could provide important information to help prevent many hearing aids being permanently discarded, and thus contribute to the quality of life of people who need hearing aids. The aim of this study was to describe preconceptions and expectations related to acquiring hearing aids among individuals aged 65 years and above. A further aim was to investigate potential dissimilarities in preconceptions and expectations between participants with mild HL compared with those with moderate/severe loss, between experienced and inexperienced hearing aid users, between men and women, between participants aged $<80$ years and those $\geq 80$ years, and between married and unmarried/widow(er)s.

\section{Material and methods}

\section{Participants}

The study was carried out at Lovisenberg Diakonale Hospital, a community hospital in Oslo, Norway, during the period from August 2007 to June 2008. A total of 193 men and women were randomly selected from a waiting list for audiologic examination and hearing aid acquisition at the Department of Otolaryngology. Inclusion criteria were that the participants were aged 65 years and above, they expressed a need for getting a hearing aid, and they had been referred by a general practitioner. Exclusion criteria were serious illness, senility, not being able to communicate in Norwegian, or not attending the initial appointment. The study sample consisted of 174 individuals (90\% response rate): 113 women $(65 \%)$ and 61 men (35\%) with an age range of 65-93 years. The mean age was 79.7 years. All participants were examined by an ear, nose, and throat specialist and were given a hearing test at their initial appointment at the hospital. HL was measured using pure tone audiometry according to recommended procedures (ISO 8253-1 1989). Air conduction thresholds were obtained separately for the left and right ear, and the frequencies 500, 1000,2000 , and $4000 \mathrm{~Hz}$ (four frequency average) were used to estimate mean HL based on the guidelines provided by the World Health Organization. The HL was, on average, $44.6 \mathrm{~dB}$. Degree of HL was categorized according to the EU Work Group on Genetics of Hearing Impairment, ${ }^{31}$ and the distribution was as follows: $<20 \mathrm{~dB} \mathrm{HL} /$ normal (no participants), 20-40 dB HL/mild (67 participants), 41-70 dB HL/moderate (101 participants), 71-90 dB HL/severe (six participants), and $>90 \mathrm{~dB} \mathrm{HL} /$ profound (no participants). There were no significant differences in $\mathrm{HL}$ according to gender. The mean age of participants with no experience using a hearing aid was 78.9, and their mean hearing level was $40.8 \mathrm{~dB}$. The mean age of participants with the experience of using a hearing aid was 80.8 years, and their mean hearing level was $50.1 \mathrm{~dB}$. HL was significantly increased in participants who were older than 80 years of age and in the experienced hearing aid users. Of the participants, $43.8 \%$ were married, and $56.2 \%$ were single, widowed, or divorced (Table 1).

Table I Demographic characteristics of the sample by hearing level $(\mathrm{N}=174)^{\prime}$

\begin{tabular}{|c|c|c|c|}
\hline & \multicolumn{2}{|c|}{ Hearing level } & \multirow[t]{2}{*}{$\%(n)$} \\
\hline & $\begin{array}{l}\leq 40 \mathrm{~dB} \\
\mathrm{HL}(\mathrm{N})\end{array}$ & $\begin{array}{l}>40 \mathrm{~dB} \\
\mathrm{HL}(\mathrm{N})\end{array}$ & \\
\hline \multicolumn{4}{|l|}{ Gender } \\
\hline Female & 46 & 67 & $64.9(113)$ \\
\hline Male & 21 & 40 & $35.1(6 I)$ \\
\hline \multicolumn{4}{|l|}{ Age } \\
\hline$<80$ years & 44 & 33 & $44.3(77)$ \\
\hline$\geq 80$ years & 23 & 74 & $55.7(97)$ \\
\hline \multicolumn{4}{|l|}{ Marital status' } \\
\hline Married & 31 & 43 & $42.5(74)$ \\
\hline Single, widow/er, divorced & 34 & 61 & $54.6(95)$ \\
\hline \multicolumn{4}{|l|}{ Hearing aid experience } \\
\hline Inexperienced & 54 & 50 & $59.8(104)$ \\
\hline Experienced & 13 & 57 & $40.2(70)$ \\
\hline
\end{tabular}

Note: 'Five missing.

Abbreviation: $\mathrm{HL}$, hearing loss. 


\section{Questionnaire}

A 10-item questionnaire was constructed based on an extensive literature review, with a specific focus on preconceptions and expectations about getting a hearing aid, external influences, the psychosocial problems associated with HL, and the problems of using a hearing aid. The questionnaire was in Norwegian and was evaluated by audiologic personnel at the Hearing Centre in Lovisenberg Diakonale Hospital. After revising the questionnaire, a pilot study was carried out with eight participants aged 65 years and above who were randomly selected from the waiting list for getting a hearing aid at the hospital. This led to some changes in formulations and exclusion of some statements. The questionnaire was tested again using six participants and was found to be suitable for its purpose. The final questionnaire, with its 10 statements (Table 2), was given to the participants, and they were asked to rank their agreement with each statement on a scale from 0 (completely agree) to 10 (completely disagree). Participants with previous hearing aid experience were asked to report the approximate number of hours they used a hearing aid per day based on six alternatives (from $\leq 1 \mathrm{~h}$ a day to $>8 \mathrm{~h}$ a day). Participants who reported that they used a hearing aid $\leq 1 \mathrm{~h}$ a day were categorized as nonusers.

\section{Data collection}

Initially, the participants included in this study received the questionnaire (Table 2). They were asked to complete the questionnaire at home and to return it within 10 days by post using an attached stamped, addressed envelope. The study was approved by the Norwegian Social Science Data Services and the National Committee for Research Ethics.

\section{Statistical analyses}

The analyses were performed using SPSS 17.0 for Windows (SPSS Inc., Chicago, IL, USA). Descriptive analyses were used to examine demographic factors (Table 1). Factor analysis with varimax rotation was conducted for the 10 items in the questionnaire, and the scale was reversed prior to analysis. The initial number of factors of interest was determined using the Kaiser rule of eigenvalues of $>1$. Subsequently, the Scree plot was investigated indicating three dimensions. Items had to obtain a loading of at least 0.4 on one factor to be considered eligible for subscale inclusion. The internal consistencies of the subscales were determined by calculating Cronbach's $\alpha$. Respondents' factor scores were computed as the sum of weighted item scores (raw score on items included in the latent variable multiplied by the item's factor loading). Sampling adequacy was assessed using Kaiser-Meyer-Olkin (KMO) statistics. When factor analysis was performed, three factors were identified. Sampling adequacy was assessed using KMO statistics with a value of 0.843 . The Scree plot suggested a two-factor model, and the Rotated Component Matrix suggested a three-factor model. The three-factor model was

Table 2 Varimax rotated factor loadings for the three-factor model of preconceptions and expectations about hearing aids

\begin{tabular}{|c|c|c|c|c|}
\hline Item & Statements & $\frac{\text { Factor I }}{\text { Positive expectations }}$ & $\frac{\text { Factor II }}{\text { Barriers }}$ & Factor III \\
\hline $\mathrm{I}$ & $\begin{array}{l}\text { I have great expectations about getting } \\
\text { a hearing aid }\end{array}$ & 0.879 & - & - \\
\hline 2 & I need to use a hearing aid every day & 0.840 & - & - \\
\hline 3 & $\begin{array}{l}\text { I believe a hearing aid will make it easier } \\
\text { to communicate with other people }\end{array}$ & 0.816 & - & - \\
\hline 4 & $\begin{array}{l}\text { I believe that in a short time I will get } \\
\text { used to my hearing aid }\end{array}$ & 0.693 & - & - \\
\hline 5 & $\begin{array}{l}\text { My goal is to use my hearing aid all } \\
\text { day long, even when l'm alone at home }\end{array}$ & 0.622 & - & - \\
\hline 6 & $\begin{array}{l}\text { I have informed people I know that } \\
\text { I am getting a hearing aid }\end{array}$ & 0.568 & - & - \\
\hline 7 & $\begin{array}{l}\text { I believe it is pretty simple to use a hearing } \\
\text { aid (ie, adjust it, put it in place, etc) }\end{array}$ & - & 0.859 & - \\
\hline 8 & $\begin{array}{l}\text { I don't believe it will be embarrassing } \\
\text { to use a hearing aid when I'm out in public }\end{array}$ & - & 0.713 & - \\
\hline 9 & $\begin{array}{l}\text { My impression is that people of my age who are } \\
\text { hard of hearing are satisfied with their hearing aid }\end{array}$ & - & 0.488 & - \\
\hline 10 & $\begin{array}{l}\text { Pressure from family and others close to me is the } \\
\text { most important reason for getting a hearing aid now }\end{array}$ & & & \\
\hline & Cronbach's $\alpha$ & 0.847 & 0.591 & 0.938 \\
\hline & Percentage of variance & 34.91 & 17.92 & 11.33 \\
\hline
\end{tabular}


selected because it was assessed to be the most meaningful according to preconceptions and expectations about getting a hearing aid. All items loaded were above the inclusion criteria of 0.4 , and no items were excluded from the analyses in the Rotated Component Matrix. As shown in Table 2, Factor I encompasses six items covering positive expectations: positive preconceptions and expectations of the benefit of a hearing aid and improved hearing in social settings. Factor II encompasses three items reflecting barriers: practical and social challenges, primarily problemoriented expectations about getting a hearing aid. Factor III consists of only one item, social pressure, and was related to the experience of pressure from family/relatives as the main reason for acquiring a hearing aid. In total, the three factors explained $64 \%$ of the total variance: Factor I: $35 \%$, Factor II: $18 \%$, and Factor III: $11 \%$. Of the total sample, Cronbach's $\alpha$ was 0.847 for Factor I and 0.591 for Factor II and could not be calculated for Factor III because this factor consisted of only one item. Cronbach's $\alpha$ was somewhat low for Factor II, according to what is conventionally regarded to be sufficient internal consistency in exploratory research (Cronbach's $\alpha>0.6) .{ }^{32}$ Cronbach's $\alpha$ for the entire questionnaire was 0.804 .

Because the distribution of the item scores deviated markedly from the normal distribution, a Mann-Whitney $U$ test was applied to examine the item score in relation to $\mathrm{HL} \leq 40$ and $>40 \mathrm{~dB}$ (Table 3 ). $P$-values of $<0.05$ and $<0.001$ were chosen as significant.

According to the distribution of HL for the majority of the participants, HL was categorized as either mild $(\leq 40 \mathrm{~dB})$ or moderate/severe $(>40 \mathrm{~dB})$. Age was categorized as $<80$

Table 3 Mean (SD) responses to the questionnaire items by hearing level ordered according to the last column

\begin{tabular}{llll}
\hline Item & $\begin{array}{l}\text { Hearing loss } \leq \mathbf{4 0} \\
\mathbf{d B}(\mathbf{n}=\mathbf{6 7})\end{array}$ & $\begin{array}{l}\text { Hearing loss }>\mathbf{4 0} \\
\mathbf{d B}(\mathbf{n}=\mathbf{I 0 7})\end{array}$ & $\begin{array}{l}\text { All subjects } \\
\mathbf{( N = 1 7 4 )}\end{array}$ \\
\cline { 2 - 4 } & Mean (SD) & Mean (SD) & Mean (SD) \\
\hline 8 & $8.58(3.01)$ & $9.78(2.14)^{*}$ & $9.31(2.58)$ \\
3 & $8.36(2.90)$ & $9.83(1.91)^{* *}$ & $9.25(2.45)$ \\
I & $7.74(2.95)$ & $9.58(2.09)^{* *}$ & $8.86(2.62)$ \\
6 & $7.53(3.86)$ & $9.67(2.36)^{* *}$ & $8.83(3.20)$ \\
4 & $7.62(2.62)$ & $9.14(2.31)^{* *}$ & $8.55(2.54)$ \\
7 & $8.15(2.59)$ & $8.72(2.76)$ & $8.50(2.70)$ \\
2 & $7.06(3.07)$ & $9.04(2.99)^{* *}$ & $8.27(3.17)$ \\
9 & $7.30(2.52)$ & $8.17(2.78)^{*}$ & $7.84(2.71)$ \\
5 & $6.34(3.56)$ & $7.58(3.38)^{*}$ & $7.10(3.49)$ \\
10 & $4.85(4.04)$ & $5.97(4.08)$ & $5.54(4.09)$ \\
\hline
\end{tabular}

Notes: $* P \leq 0.05$ by Mann-Whitney $U$ test; $* * P \leq 0.001$.

Abbreviation: SD, standard deviation. and $\geq 80$ years. Marital status was categorized as married when the participants were living with a partner and unmarried if they were single, unmarried, widowed, or divorced. Linear regression analysis was used to study the associations between subscales revealed in the factor analysis and HL, hearing aid experience, gender, age, and marital status. Factors I and II were used as dependent variables in the linear regression analysis because the distributions of these factors were close to the normal distribution. The distribution of Factor III deviated markedly from the normal distribution; hence, linear regression analysis was not performed with Factor III as a dependent variable. Instead, a Mann-Whitney $U$ test was performed on Factor III with $\mathrm{HL} \leq 40$ and $>40 \mathrm{~dB}$, hearing aid experience, gender, age, and marital status as grouping variables. A significance level of $5 \%$ was used throughout.

\section{Results}

Table 3 shows the responses to the 10 statements listed in the questionnaire. The statements are ordered according to agreement of all participants (last column) and according to $\mathrm{HL} \leq 40$ and $>40 \mathrm{~dB}$. The highest agreement among all participants was found for the items "I don't believe it will be embarrassing to use a hearing aid when I'm out in public" $($ Item 8$)($ mean $=9.31$, standard deviation $[\mathrm{SD}]=2.58)$ and "I believe a hearing aid will make it easier to communicate with other people" (Item 3$)($ mean $=9.25, \mathrm{SD}=2.45)$. Items 8 and 3 were ranked as the top two, independent of HL, gender, age, and marital status. Experienced hearing aid users reported the highest agreement with the item "I have informed people I know that I am getting a hearing aid" (Item 6) $($ mean $=9.95, \mathrm{SD}=2.01)$, followed by Items 8 and 3 in equal order. The top-ranked item for experienced hearing aid users was ranked as number six for inexperienced hearing aid users. Item 10 had the lowest agreement, independent of HL, gender, age, and marital status: "Pressure from family and others close to me is the most important reason for getting a hearing aid now" (mean $=5.54, \mathrm{SD}=4.09)$.

Participants with HL $>40 \mathrm{~dB}$ reported significantly more positive preconceptions and expectations for Items 1, 2, 3, 4, and $6(P \leq 0.001)$ and for Items 5,8 , and $9(P \leq 0.05)$ compared with those with $\mathrm{HL} \leq 40 \mathrm{~dB}$. There were no significant differences regarding HL for Items 7 and 10.

Based on the three factors from the factor analysis, positive expectations (Factor I) were significantly associated with $\mathrm{HL}>40 \mathrm{~dB}$ and previous hearing aid experience, $P \leq 0.001$ and $P \leq 0.001$, respectively. Fewer barriers (Factor II) toward 
hearing aids were significantly associated with $\mathrm{HL}>40 \mathrm{~dB}$ ( $P \leq 0.001)$, previous hearing aid experience $(P \leq 0.05)$, and male gender $(P \leq 0.05)$. There were no significant differences between groups regarding social pressure (Factor III) using the Mann-Whitney $U$ test. Age and marital status had no influence on the three factors.

Table 4 presents the results from the linear regression analysis. When analyzing HL, hearing aid experience, gender, age, and marital status simultaneously in an adjusted linear regression analysis, $\mathrm{HL}>40 \mathrm{~dB}(P \leq 0.001)$ and hearing aid experience $(P \leq 0.05)$ were positively and significantly associated with positive expectations (Factor I). Only male gender $(P \leq 0.05)$ was positively and significantly associated with barriers (Factor II). Social pressure (Factor III) was not significantly associated with HL, hearing aid experience, gender, age, or marital status.

\section{Discussion}

Expectations and preconceptions about hearing aids were grouped into three factors: positive expectations, barriers, and social pressure, with positive expectations accounting for the largest proportion of the variance. $\mathrm{HL}>40 \mathrm{~dB}$ and hearing aid experience were both associated with positive expectations. Men reported fewer barriers to hearing aids than women did.

\section{Preconceptions and expectations}

This cross-sectional study was designed to investigate the preconceptions and expectations in a clinical sample of older adults who had been referred for getting hearing aids. Positive expectations were found to explain a large proportion of the variance in the present factor analysis. The effect remained after controlling for HL, hearing aid experience, age, gender, and marital status. The positive expectations stated in this study may at least partly be influenced by a high willingness to get a hearing aid among those seeking medical advice for their problem. Such individuals are found to be more pragmatic and empowered in dealing with life's challenges ${ }^{33}$ and to have more self-awareness of their hearing difficulties. ${ }^{34}$ Previous studies have shown that it is necessary to encourage positive expectations to increase motivation to use a hearing aid..$^{24,29,35}$ Nevertheless, it should be emphasized that it takes more than positive expectations to succeed. Therefore, it might be advantageous to identify incentives and to set goals. This could reveal lack of motivation among subjects seeking audiologic support, and it might be important for how the rehabilitation process progresses. Investing time, being willing to use the hearing aid regularly, and being open to the challenges of having a hearing impairment are also prerequisites. A discussion of this at an early stage in the provision of a hearing aid may encourage responsibility and autonomy in the rehabilitation process.

\section{Barriers}

The second factor relating to preconceptions and expectations about hearing aid use was barriers to hearing aids. The fact that men reported fewer barriers to the use of hearing aids could be explained by higher motivation among those who apply for such devices. There were almost twice as many women as men in the study sample, and further investigation is needed to explore the reason for this distribution. The finding that age was not related to preconceptions and expectations about hearing aids suggests that older adults' expectations about getting a hearing aid are not related to age. On the other hand, this could also indicate that their expectations are unrealistic considering their reduced health and physical limitations. Thus, the advantages of being selfreliant in using a hearing aid should be emphasized; the physical capacity and visual abilities of the individual should be considered. Sufficient time for individual support should also be provided during the period when the hearing aid is being adjusted. Further, barriers are also associated with

Table 4 Linear regression results for preconception factors: positive expectations (Factor I) and barriers (Factor II)

\begin{tabular}{|c|c|c|c|c|c|c|}
\hline & \multicolumn{3}{|c|}{ Factor I } & \multicolumn{3}{|c|}{ Factor II' } \\
\hline & B & $95 \% \mathrm{Cl}$ & $P$ & B & $95 \% \mathrm{Cl}$ & $P$ \\
\hline \multicolumn{7}{|l|}{ Hearing loss } \\
\hline$>40 \mathrm{~dB} H \mathrm{HL}$ vs $\leq 40 \mathrm{~dB} \mathrm{HL}$ & 6.21 & $3.13-9.28$ & $<0.001$ & - & - & - \\
\hline \multicolumn{7}{|l|}{ Hearing aid experience } \\
\hline Yes vs no & 3.90 & $0.85-6.96$ & 0.013 & - & - & - \\
\hline \multicolumn{7}{|l|}{ Gender } \\
\hline Male vs female & - & - & - & 1.80 & $0.43-3.16$ & 0.010 \\
\hline$R^{2}$ & 0.17 & - & - & 0.10 & - & - \\
\hline
\end{tabular}

Notes: 'High loading for Factor II means few barriers.

Abbreviations: $\mathrm{Cl}$, confidence interval; $\mathrm{HL}$, hearing loss. 
psychosocial aspects. ${ }^{21,36}$ Stigmatization has been frequently mentioned in previous studie ${ }^{23-25}$ and should be taken into account. By focusing on incentives for getting a hearing aid, achieving individual goals, and identifying mental and physical barriers, people with hearing impairments would be encouraged to gain skills that would benefit them in the short and long term.

\section{The impact of HL}

Previous studies have shown a relationship between selfreported $\mathrm{HL}$ and the outcome of hearing aid use. ${ }^{8,22}$ We had the opportunity to estimate how measured HL was related to expectations about a hearing aid. Participants with minor HL expressed lower expectations about hearing aids (Item 1) and had fewer plans for using hearing aids regularly (Item 5). They also reported less need (Item 2). This suggests that positive preconceptions and expectations are insufficient. The user must also be willing to use the hearing aid. Lower expectations among participants with mild HL could probably be explained by a more modest need for amplification. Accordingly, this group may not be convinced of the potential benefit of hearing amplification. It is apparent that lack of motivation for using hearing aids, a bigger barrier against using a hearing aid, and low self-estimated need for using a hearing aid are factors that work against an individual becoming a competent hearing aid user. ${ }^{21,35-37}$ These findings point to the need for emphasizing that adapting to a hearing aid is a time-consuming process that requires perseverance, motivation, and time.

\section{The impact of hearing aid experience}

Positive expectations toward acquiring a hearing aid were related to previous experience and correspond well with the findings of another study, which demonstrated that experienced hearing aid users were also the most motivated. ${ }^{21}$ This may indicate that the most contented hearing aid users are those who return to get a new hearing aid. Further studies are required to investigate this hypothesis. The fact that first-time hearing aid users intended to use their hearing aid less than experienced hearing-aid users challenges the outcome of the rehabilitation process, both in terms of reluctance to getting a hearing aid and to adapting to using it. Unrealistically high expectations about hearing aid use among new hearing aid users have been reported previously. ${ }^{18}$ Nevertheless, this study found that new hearing aid users had lower expectations than experienced users. These contradictory findings probably have more than one explanation. There are obvious reasons for satisfied hearing aid users to seek refitting. On the other hand, many unsatisfied users may give up trying and gradually stop using their hearing aids. Presumably, many first-time users of hearing aids have also consulted other hearing aid users prior to the referral. Our study showed that firsttime users assessed people with hearing impairments at their age to be less satisfied with their hearing aids compared with experienced hearing aid users' assessments (Item 9). This preconception about hearing aids could explain the lower expectations and might have an effect on the outcome. Older adults with subjectively lower estimated need who are reluctant to use a hearing aid may represent many of the individuals provided with a hearing aid but not using it regularly, if at all. ${ }^{8-10,16}$ Therefore, emphasis should be put on continuity and regular use in the initial stage of the rehabilitation process. In addition, this indicates that there should perhaps be a prescribed number of hours per day for hearing aid use during the habituation period.

\section{Methodological limitations}

In spite of the high response rate of $90 \%$ in this sample, a generalization of the results to the total population of older hearing-impaired adults is not considered possible. The reasons for this reservation are mainly the exclusion of individuals with serious illness and senility, those who could not read or communicate in Norwegian, and those who did not attend the initial appointment. Another factor might be the findings of Cox et al suggesting that subjects who use public health services in the USA (Veterans Affairs) have been found to report higher expectations from hearing aids and more severe unaided problems compared with patients with similar audiograms seeking private practice..$^{38}$ Even though the American health care system is not organized in a similar way to the Norwegian health care system, dissimilarity in attitudes between subjects seeking private practice versus public health clinics could be relevant in Norway as well. The questionnaire was not validity tested apart from the evaluations made by professionals, the pilot testing, and the retesting. Therefore, a selection bias could have influenced the results.

\section{Conclusion}

This study shows that experienced hearing aid users and participants with $\mathrm{HL}>40 \mathrm{~dB}$ had significantly higher expectations about hearing aids compared with inexperienced participants and participants with less HL. Men had fewer barriers about getting hearing aids than women did. Lower expectations and more problem-oriented preconceptions 
among participants with milder HL could be an explanation for the large number of hearing aids being unused. Lower estimated need and modest plans for regular use among this group could also lead to hearing aids not being used. In the process of getting used to using a hearing aid, there should be a focus on investment of time, continuity of use, and positive expectations. Follow-up appointments should be recommended, especially for those with milder HL and those without previous hearing aid experience.

\section{Acknowledgments}

I thank the Norwegian Foundation for Health and Rehabilitation (the Norwegian Association of the Hearing Impaired, HLF) for providing the EXTRA funds. I also thank Lovisenberg Diakonale Hospital for practical and financial support. This study was conducted independent of the funding agencies. I also express my sincere appreciation to Kari Jorunn Kværner and Eva-Signe Falkenberg for their valuable help and for critical reading of this manuscript. Finally, I thank Kristin Bakke Lysdahl, Leiv Sandvik, and Britt Øverland for their statistical support.

\section{Disclosure}

The author reports no conflict of interest, and the author alone is responsible for the content and writing of this article.

\section{References}

1. Davis AC. Epidemiology of hearing disorder. In: Kerr AG, editor. Scott Brown's Otolaryngology. Boston: Butterworth-Heineman; 1997:2/3/1-2/3/38.

2. Ries PW. Prevalence and characteristics of persons with hearing trouble: United States, 1990-91. Vital Health Stat 10. 1994;188:1-75.

3. Davis AC. The prevalence of hearing impairment and reported hearing disability among adults in Great Britain. Int J Epidemiol. 1989;18(4): 911-917.

4. Wilson DH, Walsh PG, Sanchez L, et al. The epidemiology of hearing impairment in an Australian adult population. Int J Epidemiol. 1999;28(2):247-252.

5. Cruickshanks KJ, Wiley TL, Tweed TS, et al. Prevalence of hearing loss in older adults in Beaver Dam, Wisconsin. The Epidemiology of Hearing Loss Study. Am J Epidemiol. 1998;148(9):879-886.

6. Tambs K. Utbredelse av hørselstap. Prevalence of hearing impairment in Norway. Nytt fra Miljø og Samfunnsmedisin. 1998;2:1.

7. Parving A, Sibelle P. Clinical study of hearing instruments: a crosssectional longitudinal audit based on consumer experiences. Audiology. 2001;40(1):43-53.

8. Popelka MM, Cruickshanks KJ, Wiley TL, Tweed TS, Klein BE, Klein R. Low prevalence of hearing aid use among older adults with hearing loss: the Epidemiology of Hearing Loss Study. J Am Geriatr Soc. 1998;46(9):1075-1078.

9. Smeeth L, Fletcher AE, Ng ES, et al. Reduced hearing, ownership, and use of hearing aids in elderly people in the UK - the MRC Trial of the Assessment and Management of Older People in the Community: a cross-sectional survey. Lancet. 2002;359(9316):1466-1470.

10. Stark P, Hickson L. Outcomes of hearing aid fitting for older people with hearing impairment and their significant others. Int J Audiol. 2004 43(7):390-398.
11. Stephens D, Lewis P, Davis A, Gianopoulos I, Vetter N. Hearing aid possession in the population: lessons from a small country. Audiology. 2001;40(2):104-111.

12. Falkenberg E-S. Holistic aural rehabilitation: a challenge. Scand J Disabil Res. 2007;9(2):78-90.

13. Meister H, Lausberg I, Kiessling J, von Wedel H, Walger M. Identifying the needs of elderly, hearing-impaired persons: the importance and utility of hearing aid attributes. Eur Arch Otorhinolaryngol. 2002;259(10): 531-534.

14. Gimsing S. Use of hearing aids five years after issue. Ugeskr Laeger. 2008;170(43):3407-3411.

15. Vuorialho A, Karinen P, Sorri M. Effect of hearing aids on hearing disability and quality of life in the elderly. Int J Audiol. 2006;45(7): 400-405.

16. Lupsakko TA, Kautiainen HJ, Sulkava R. The non-use of hearing aids in people aged 75 years and over in the city of Kuopio in Finland. Eur Arch Otorhinolaryngol. 2005;262(3):165-169.

17. Bertoli S, Staehelin K, Zemp E, Schindler C, Bodmer D, Probst R. Survey on hearing aid use and satisfaction in Switzerland and their determinants. Int J Audiol. 2009;48(4):183-195.

18. Cox RM, Alexander GC. Expectations about hearing aids and their relationship to fitting outcome. J Am Acad Audiol. 2000;11(7):368-382.

19. Schum DJ. Perceived hearing aid benefit in relation to perceived needs J Am Acad Audiol. 1999;10(1):40-45.

20. Kricos PB, Lesner SA, Sandridge SA. Expectations of older adults regarding the use of hearing aids. J Am Acad Audiol. 1991;2(3):129-133.

21. Van den Brink RH, Wit HP, Kempen GI, van Heuvelen MJ. Attitude and help-seeking for hearing impairment. Br J Audiol. 1996;30(5): 313-324.

22. Brooks DN, Hallam RS. Attitudes to hearing difficulty and hearing aids and the outcome of audiological rehabilitation. Br JAudiol. 1998;32(4): 217-226.

23. Erler SF, Garstecki DC. Hearing loss- and hearing aid-related stigma: perceptions of women with age-normal hearing. Am J Audiol. 2002; 11(2):83-91.

24. Meister H, Walger M, Brehmer D, von Wedel UC, von Wedel H. The relationship between pre-fitting expectations and willingness to use hearing aids. Int $J$ Audiol. 2008;47(4):153-159.

25. Biering-Sorensen M, Christensen B, Sorensen MS, Parving A. The Valby Project: a survey of hearing in the elderly $\geq 80$ years of age not provided with hearing aids. Scand Audiol. 1997;26(1):33-41.

26. Duijvestijn JA, Anteunis LJ, Hoek CJ, van den Brink RH, Chenault MN, Manni JJ. Help-seeking behaviour of hearing-impaired persons aged $\geq 55$ years; effect of complaints, significant others and hearing aid image. Acta Otolaryngol. 2003;123(7):846-850.

27. Espmark AK, Rosenhall U, Erlandsson S, Steen B. The two faces of presbyacusis: hearing impairment and psychosocial consequences. Int $J$ Audiol. 2002;41(2):125-135.

28. Mahoney CF, Stephens SD, Cadge BA. Who prompts patients to consult about hearing loss? Br J Audiol. 1996;30(3):153-158.

29. Wilson C, Stephens D. Reasons for referral and attitudes toward hearing aids: do they affect outcome? Clin Otolaryngol Allied Sci. 2003;28(2):81-84.

30. Karlsson AK, Rosenhall U. Aural rehabilitation in the elderly: supply of hearing aids related to measured need and self-assessed hearing problems. Scand Audiol. 1998;27(3):153-160.

31. Martini A. European working group on genetics of hearing impairment: European Commission Directorate, Biomedical and Health Research Programme (HEAR). Infoletter. 1996 Nov 2:8.

32. Garson G. Reliability Analysis Statnotes: Topics in Multivariate Analysis. 2008. Available from: htpp://faculty.chass.ncsu.edu/garson/ PA765/reliab.htm. Accessed 2010 Nov 29.

33. Cox RM, Alexander GC, Gray GA. Who wants a hearing aid? Personality profiles of hearing aid seekers. Ear Hear. 2005;26(1):12-26.

34. Cox RM, Alexander GC, Gray GA. Personality, hearing problems, and amplification characteristics: contributions to self-report hearing aid outcomes. Ear Hear. 2007;28(2):141-162. 
35. Weinstein BE. Age-related hearing loss: how to screen for it, and when to intervene. Geriatrics. 1994;49(8):40-45.

36. Thomas AJ. Rehabilitation of adults with acquired hearing loss: the psychological dimension. Br J Audiol. 1988;22(2):81-83.

37. Rosenhall U. The influence of ageing on noise-induced hearing loss. Noise Health. 2003;5(20):47-53.
38. Cox RM, Alexander GC, Gray GA. Hearing aid patients in private practice and public health (Veterans Affairs) clinics: are they different? Ear Hear. 2005;26(6):513-528.

\section{Publish your work in this journal}

The Journal of Multidisciplinary Healthcare is an international, peerreviewed open-access journal that aims to represent and publish research in healthcare areas delivered by practitioners of different disciplines. This includes studies and reviews conducted by multidisciplinary teams as well as research which evaluates the results or conduct of such teams or healthcare processes in general. The journal covers a wide range of areas and welcomes submission from practitioners at all levels, from all over the world. The manuscript management system is completely online and includes a very quick and fair peer-review system. Visit http://www.dovepress.com/testimonials.php to read real quotes from published authors.

Submit your manuscript here: http://www.dovepress.com/journal-of-multidisciplinary-healthcare-journal 